Repository of the Max Delbrück Center for Molecular Medicine (MDC) Berlin (Germany)

http://edoc.molc-berlin.de/eprintid/11125

\title{
Do CARs Need a Driver's License? Adoptive Cell Therapy with Chimeric Antigen Receptor-Redirected T Cells Has Caused Serious Adverse Events
}

Hildegard Büning, Wolfgang Uckert, Klaus Cichutek, Robert E. Hawkins, and Hinrich Abken

This is a copy of an article published in the "Human Gene Therapy" (C) 2010 copyright Mary Ann Liebert, Inc.; "Human Gene Therapy" is available online at: http://online.liebertpub.com. 


\title{
Do CARs Need a Driver's License? Adoptive Cell Therapy with Chimeric Antigen Receptor-Redirected T Cells Has Caused Serious Adverse Events
}

\author{
Hildegard Büning,, Wolfgang Uckert, ${ }^{1}$ Klaus Cichutek, ${ }^{3}$ Robert E. Hawkins, ${ }^{4}$ and Hinrich Abken ${ }^{1}$
}

$\mathbf{M}$ ETASTATIC CANCER STILL remains difficult to treat; although most new agents are of clear palliative benefit for the majority of patients, they frequently do not control cancer in the long term. Immunotherapy, by contrast, can result in long-term benefits even after short-term treatment. In particular, adoptive transfer of autologous tumor-infiltrating lymphocytes (TILs) in combination with a nonmyeloablative lymphodepletion regimen has resulted in greater than $70 \%$ response rates in melanoma, with proven durability at least in some cases (Dudley et al., 2005, 2008). Although these and other data indicate the potential of adoptive cell therapy, the strategy is technically challenging: first, TILs must be isolated from surgical tumor specimens, which is particularly difficult in the case of solid tumors, and second, tumor-reactive T cells must be identified and expanded to sufficient numbers for therapeutic application. The procedure can be simplified by ex vivo modification of primary human lymphocytes from the cancer patient with a recombinant receptor molecule, such as a chimeric antigen receptor (CAR), of predefined specificity for cancer cells (Eshhar, 2008; Vera et al., 2009). The chimeric antigen receptor is composed of an extracellular, antibodyderived antigen-binding domain fused to an intracellular, $\mathrm{T}$ cell receptor (TCR)-derived CD3 $\zeta$ domain to provide $\mathrm{T}$ cell activation on engagement of antigen. By using an antibody for binding, CAR recognition of antigen becomes independent of antigen processing and presentation by the major histocompatibility complex, both frequently altered in tumors, and is moreover suitable for recognition of nonclassical $\mathrm{T}$ cell antigens including carbohydrates.

Although cytotoxic $\mathrm{T}$ lymphocytes (CTLs) engineered with a tumor-associated antigen-specific CAR induced tumor cell lysis in vitro and eradicated transplanted tumors in a variety of mouse models, in the first clinical trials the therapeutic efficacy of CAR-engineered T cells was limited (Kershaw et al., 2006; Lamers et al., 2006; Till et al., 2008). This was thought to be due to transient $\mathrm{T}$ cell activation and poor in vivo persistence due to the lack of the second (costimulatory) signal, which is necessary - in addition to TCR signalingto evade anergy induction. Second-generation CARs consequently possess a costimulatory moiety derived from CD28, OX40 (CD134), or 4-1BB (CD137) together with CD3 $\zeta$ in the intracellular domain to improve $\mathrm{T}$ cell activation and expansion. To further improve $\mathrm{T}$ cell activation and persistence, the CD28 and 4-1BB domains were subsequently combined, leading to third-generation CARs (Carpenito et al., 2009; Zhao et al., 2009).

An increasing number of clinical trials are currently evaluating second- and third-generation CARs in the treatment of malignant diseases. Although some of them produced encouraging preliminary evidence of clinical efficacy (Brentjens et al., 2010a), two serious adverse events (SAEs) were reported. In the trial performed by the Surgery Branch at the National Institutes of Health (NIH, Bethesda, MD), a patient with refractory colon cancer with lung and liver metastases received, after nonmyeloablative lymphodepletion, $10^{10} \mathrm{~T}$ cells engineered with an anti-ErbB2 thirdgeneration CAR allowing for CD28 and 4-1BB costimulation (Morgan et al., 2010). Immediately after infusion the patient developed dramatic pulmonary toxicity with lung infiltrates and a cytokine storm with increased levels of interferon (IFN)- $\gamma$, granulocyte-macrophage colony-stimulating factor (GM-CSF), tumor necrosis factor (TNF)- $\alpha$, interleukin (IL)-6, and IL-10 followed by cardiac arrest. The patient died on day 5 after treatment. On the basis of extensive postmortem analyses the investigators concluded that the toxicity was likely due to the accumulation of a large number of modified T cells

\footnotetext{
${ }^{1}$ Zentrum für Molekulare Medizin Köln and Klinik I für Innere Medizin, Uniklinik Köln, D-50937 Cologne, Germany.

${ }^{2}$ Max-Delbrück-Centrum für Molekulare Medizin, D-13125 Berlin-Buch, Germany.

${ }^{3}$ Paul Ehrlich Institut, D-63225 Langen, Germany.

${ }^{4}$ Department of Medical Oncology, Paterson Institute of Cancer Research, University of Manchester, Manchester, M20 4BX, UK.

H.B. is president and W.U. is scientific secretary of the German Society for Gene Therapy (DG-GT); K.C. is president of the Paul Ehrlich Institute; W.U., R.E.H., and H.A. are members of the ATTACK consortium.
} 
in the lung and their cytokine release on binding to ErbB2, which is physiologically expressed at low levels on lung epithelia. The second SAE occurred in the trial performed at the Memorial Sloan-Kettering Cancer Center (New York, NY): an extensively pretreated, lymphodepleted patient with chronic lymphocytic leukemia (CLL) developed hypotension, dyspnea, and fever after infusion of T cells engineered with an anti-CD19 second-generation CAR containing the CD28 domain at a total dose of $3 \times 10^{7} \mathrm{~T}$ cells $/ \mathrm{kg}$. In contrast to patients in the first cohort of the trial, who received the same number of $\mathrm{T}$ cells without developing significant adverse events, this patient was the first to receive a cyclophosphamide pretreatment for lymphodepletion followed by $\mathrm{T}$ cell infusion. The autopsy did not reveal an obvious cause of death; however, investigators assume that low-grade sepsis present before $\mathrm{T}$ cell infusion may have triggered the observed elevated cytokine levels and that cyclophosphamide used for lymphodepletion may have mediated a cytokine storm, which in turn boosted activation of transferred modified $\mathrm{T}$ cells. The immune-modulatory effect of cyclophosphamide in this context is probably multifactorial and several, mutually nonexclusive mechanisms may be envisaged: enhanced homeostatic expansion of modified $\mathrm{T}$ cells by the creation of a niche; induction of $\mathrm{T}$ cell growth factors including type I interferons; stimulation of innate immune cells, particularly dendritic cells; and elimination of regulatory $\mathrm{T}$ cells. Although these proposed mechanisms are still controversial, they have each been proposed on the basis of specific models in which cyclophosphamide was injected into tumor-bearing hosts before adoptive transfer of in vitroexpanded tumor-specific T cells (Dudley et al., 2005).

While the CARs used in these trials showed efficient antitumor activity in mouse models (Brentjens et al., 2007; Zhao et al., 2009), autoreactivity may be difficult to predict, in particular if it varies from patient to patient. However, redirected activation of $\mathrm{T}$ cells obviously needs to be better tuned in vivo, a drawback that is currently impaired by a number of factors. In the following we discuss some drawbacks and potential solutions.

Adoptive transfer of CAR-engineered T cells is thought to be a specific targeting approach defined by the antibodyderived binding domain of the CAR. However, apart from B lymphoma idiotypes, CAR-targeted antigens are frequently found on healthy tissue, although expressed at lower levels. As a consequence, CAR-directed $\mathrm{T}$ cell attack on healthy tissue may result in severe toxicity ("on-target off-organ" toxicity). Even short-term $\mathrm{T}$ cell persistence seems to be sufficient to produce significant toxicity as evident from studies with first-generation CAR-modified $\mathrm{T}$ cells. For instance $T$ cells modified with a first-generation CAR specific for carbonic anhydrase IX, expressed on renal cell carcinoma, induced reversible yet discrete cholangitis and damage to bile duct epithelium due to target antigen expression on those cells, although at low levels (Lamers et al., 2006). T cells modified with a MART-1 (melanoma antigen recognized by $\mathrm{T}$ cells)-specific TCR induced inner ear and retina toxicity due to antigen expression in these organs at similar levels as on targeted melanoma cells (Johnson et al., 2009). These examples highlight the need to discriminate between tumor cells expressing the antigen at a high level and those cells with physiological medium- or low-level expression of the same antigen. As discrimination is, at least in part, impacted by the CAR binding affinity/avidity, use of low-affinity antibodies may overcome this problem.

Currently used CAR binding domains are derived from high-affinity antibodies or are optimized for high-affinity binding. In the NIH trial the CAR binding domain was based on the widely used humanized antibody trastuzumab (Herceptin) and had a high binding affinity, that is, $K_{\mathrm{D}}=0.3 \mathrm{nM}$ (Zhao et al., 2009). Hence, CAR binding affinity was much higher than the avidity of the physiological TCR. High-affinity binding, however, is less discriminative between moderate and high antigen amounts on target cells, resulting in CAR-triggered T cell activation also on binding to cells with moderate antigen levels, as found on healthy tissues. An increase in binding affinity above threshold thereby does not increase $\mathrm{T}$ cell activation with respect to cytokine release and cytolysis, which would be advantageous for immunotherapeutic approaches, but results in a loss of selectivity for high-level antigen-expressing targets (Chmielewski et al., 2005). Consequently, moderate- or even low-affinity CARs that need higher antigen levels to efficiently trigger $T$ cell activation may target more selectively tumor cells with high antigen load.

Combining $\mathrm{CD} 3 \zeta$ and costimulation allowed the limited efficacy of first-generation CARs to be overcome and improved cytokine secretion and cytolytic activity. The CAR in the NIH trial was combined with CD28 and 4-1BB costimulatory molecules, whereas in the Sloan-Kettering trial CD28 costimulation was used to improve T cell activation. In the NIH trial a lethal cytokine storm occurred immediately after $\mathrm{T}$ cell infusion, whereas the cytokine storm in other trials, such as the Rotterdam trial (Lamers et al., 2006), occurred hours or days later. Forced CD28 costimulation as it occurs by combined CD28 and 4-1BB costimulation may predestine the recipient for a cytokine storm, as does administration of the superagonistic anti-CD28 antibody (Suntharalingam et al., 2006). An alternative, perhaps more manageable approach for providing the costimulatory signal is to express a first-generation CAR in the absence of costimulatory domains on virus-specific $\mathrm{T}$ cells, which then receive costimulation by antigen engagement through their native TCR on antigen-presenting cells (APCs) (Cooper et al., 2005; Pule et al., 2008). This strategy is supported by a trial (Pule et al., 2008) in which selected Epstein-Barr virus (EBV)-specific $\mathrm{T}$ cells modified with a neuroblastoma-associated antigenspecific CAR showed longer in vivo persistence than unselected $\mathrm{T}$ cells with the same CAR that did not receive costimulation by EBV antigen-presenting cells.

Other domains within CARs may also affect "off-target" activation. Some trials currently in planning use the IgG1 $\mathrm{C}_{\mathrm{H}} 2-\mathrm{C}_{\mathrm{H}} 3$ domain as a spacer in the extracellular moiety between the binding and transmembrane domains to improve CAR expression and target binding. This particular IgG1 spacer, however, has been shown to bind to Fc receptorexpressing cells in vitro, including monocytes and natural killer (NK) cells, leading to their activation and release of proinflammatory cytokines (Hombach et al., 2010). CARmodified $\mathrm{T}$ cells may also become activated through CAR cross-linking by $\mathrm{F}_{\mathrm{C}}$ receptor binding, which results in cytokine release and cytolysis of the engaged cells. This process may contribute to initiate an "off-organ" innate response and to sustain a cytokine storm. The side effect may be reduced 
by modifying the IgG1 spacer domain to reduce $F_{c}$ receptor binding (Hombach et al., 2010). The issue of IgG spacerassociated "off-target" activation, however, does not hold true for the NIH trial, which used a CD8 hinge, or for the Sloan-Kettering trial, in which the CAR binding domain was directly linked to the CD28 transmembrane moiety.

The dose at which $\mathrm{T}$ cells are administered is, moreover, crucial for first trials conducted in humans. A more restricted dose escalation scheme for initial studies in humans, starting with doses that are unlikely to cause serious toxicity, is recommended by investigators in the NIH study (Morgan et al., 2010). First infusion of low-dose T cells or prolonged infusion over 2 days, with one-third given the first day and two-thirds the second day, as in the modified Sloan-Kettering trial (Brentjens et al., 2010b), may prevent the immediate onset of severe adverse events. Both strategies will help to define the therapeutic window; in addition, low numbers of infused $\mathrm{T}$ cells need more time to expand to numbers that may cause severe toxicity, giving more time for therapeutic interventions. Modified T cells targeting antigens in those organs to which they nonspecifically localize immediately after infusion, such as the lungs and liver, may more rapidly cause SAEs than $\mathrm{T}$ cells targeting antigens on organs that are later and less efficiently infiltrated. Apart from that, administration to a single patient followed by a suitable waiting period and other measures described in the guidelines for first use of novel medicinal products in humans should generally be considered.

Once SAEs became clinically apparent in the Rotterdam trial, steroids were administered to stop the autoaggression and to eliminate most of the modified $\mathrm{T}$ cells in circulation (Lamers et al., 2006). Steroid application is generally effective, as demonstrated in allogeneic donor lymphocyte infusions to abrogate graft-versus-host disease (Ciceri et al., 2009). In addition, $\mathrm{T}$ cells can be engineered with a herpes simplex virus thymidine kinase (TK) gene to allow elimination of modified T cells by application of nucleoside prodrugs. Experimental models, however, imply limited safety due to insufficient kinase activity, which can be partially compensated by coexpression of a second suicide gene (Uckert et al., 1998). Alternatively, inducible caspase-9 has been expressed in CAR-modified T cells to cause apoptosis, which is brought about by administration of a dimerizer that forms the active enzyme from two nonfunctional molecules (Tey et al., 2007; de Witte et al., 2008). CD19-specific CAR-engineered T cells have been modified with inducible caspase- 9 to improve safety (Hoyos et al., 2010). T cells engineered with a Myc tag incorporated in the transgenic TCR $\alpha$-chain were efficiently eliminated in an experimental mouse system by administration of a depleting anti-Myc antibody (Kieback et al., 2008). This safeguard has the advantage that it does not depend on high-level expression of a second transgene besides the CAR, and the elimination is specific and not toxic to other cells. An alternative strategy is based on transient CAR expression in modified $\mathrm{T}$ cells, instead of the stable expression achieved with the commonly used retro- or lentiviral vectors. Coding RNA is transferred by electroporation into $\mathrm{T}$ cells, which subsequently express CARs and execute redirected cytolytic functions toward target cells (Birkholz et al., 2009). The expanding RNA-modified T cells gradually lose CAR expression, with a half-life of about 2 days, whereas nonactivated $\mathrm{T}$ cells continue to express CARs for several days in vitro. Transient CAR expression will thereby be of advantage in exploring immediate toxicity in initial human applications. Of course, the efficacy of this approach must be clinically tested to ensure that the intended effect can be achieved in humans.

Great credit must be given to the investigators in both trials for presenting detailed reports to the scientific community, which will help to make CAR-redirected $\mathrm{T}$ cell therapy safer in the treatment of cancer.

\section{Author Disclosure Statement}

No competing financial interests exist.

\section{References}

Birkholz, K., Hombach, A., Krug, C., Reuter, S., Kershaw, M., Kämpgen, E., Schuler, G., Abken, H., Schaft, N., and Dörrie, J. (2009). Transfer of mRNA encoding recombinant immunoreceptors reprograms $\mathrm{CD}^{+}$and $\mathrm{CD}^{+} \mathrm{T}$ cells for use in the adoptive immunotherapy of cancer. Gene Ther. 16, 596604.

Brentjens, R., Yeh, R., Bernal, Y., Riviere, I., and Sadelain, M. (2010a). Treatment of chronic lymphocytic leukemia with genetically targeted autologous $\mathrm{T}$ cells: Case report of an unforeseen adverse event in a phase I clinical trial. Mol. Ther. 18, 666-668.

Brentjens, R., Riviere, I., Frattini, M., Wang, Y., Taylor, C., Olszewska, M. Borquez-Ojeda, O., Bartido, S., Stefanski, J., Yeh, R., and Sadelain, M. (2010b). Marked regression of adenopathy following infusion of autologous $\mathrm{T}$ cells genetically targeted to the CD19 antigen in a patient with bulky CLL. Abstract presented at the 13th Annual Meeting of the American Society of Gene and Cell Therapy, May 17-22, 2010, Washington, D.C.

Brentjens, R.J., Santos, E., Nikhamin, Y., Yeh, R., Matsushita, M., La Perle, K., Quintás-Cardama, A., Larson, S.M., and Sadelain, M. (2007). Genetically targeted T cell eradicate systemic acute lymphoblastic leukemia xenografts. Clin. Cancer Res. 13, 5426-5435.

Carpenito, C., Milone, M.C., Hassan, R., Simonet, J.C., Lakhal, M., Suhoski, M.M., Varela-Rohena, A., Haines, K.M., Heitjan, D.F., Albelda, S.M., Carroll, R.G., Riley, J.L., Pastan, I., and June, C.H. (2009). Control of large, established tumor xenografts with genetically retargeted human $\mathrm{T}$ cells containing CD28 and CD137 domains. Proc. Natl. Acad. Sci. U.S.A. 106, 3360-3365.

Chmielewski, M., Hombach, A., Heuser, C., Adams, G.P., and Abken, H. (2004). T cell activation by antibody-like immunoreceptors: Increase in affinity of the single-chain fragment domain above threshold does not increase $\mathrm{T}$ cell activation against antigen-positive target cells but decreases selectivity. J. Immunol. 173, 7647-7653.

Ciceri, F., Bonini, C., Stanghellini, M.T., Bondanza, A., Traversari, C., Salomoni, M., Turchetto, L., Colombi, S., Bernardi, M., Peccatori, J., Pescarollo, A., Servida, P., Magnani, Z., Perna, S.K., Valtolina, V., Crippa, F., Callegaro, L., Spoldi, E., Crocchiolo, R., Fleischhauer, K., Ponzoni, M., Vago, L., Rossini, S., Santoro, A., Todisco, E., Apperley, J., Olavarria, E., Slavin, S., Weissinger, E.M., Ganser, A., Stadler, M., Yannaki, E., Fassas, A., Anagnostopoulos, A., Bregni, M., Stampino, C.G., Bruzzi, P., and Bordignon, C. (2009). Infusion of suicidegene-engineered donor lymphocytes after family haploidentical haemopoietic stem-cell transplantation for leukaemia (the 
TK007 trial): A non-randomised phase I-II study. Lancet Oncol. 10, 489-500.

Cooper, L.J., Al-Kadhimi, Z., Serrano, L.M., Pfeiffer, T., Olivares, S., Castro, A., Chang, W.C., Gonzalez, S., Smith, D., Forman, S.J., and Jensen, M.C. (2005). Enhanced anti-lymphoma efficacy of CD19-redirected influenza MP1-specific CTLs by cotransfer of T cells modified to present influenza MP1. Blood 105, 1622-1631. de Witte, M.A., Jorritsma, A., Swart, E., Straathof, K.C., de Punder, K., Haanen, J.B., Rooney, C.M., and Schumacher, T.N. (2008). An inducible caspase-9 safety switch can halt cell therapy-induced autoimmune disease. J. Immunol. 180, 63656373.

Dudley, M.E., Wunderlich, J.R., Yang, J.C., Sherry, R.M., Topalian, S.L., Restifo, N.P., Royal, R.E., Kammula, U., White, D.E., Mavroukakis, S.A., Rogers, L.J., Gracia, G.J., Jones, S.A., Mangiameli, D.P., Pelletier, M.M., Gea-Banacloche, J., Robinson, M.R., Berman, D.M., Filie, A.C., Abati, A., and Rosenberg, S.A. (2005). Adoptive cell transfer therapy following non-myeloablative but lymphodepleting chemotherapy for the treatment of patients with refractory metastatic melanoma. J. Clin. Oncol. 23, 2346-2357.

Dudley, M.E., Yang, J.C., Sherry, R., Hughes, M.S., Royal, R., Kammula, U., Robbins, P.F., Huang, J., Citrin, D.E., Leitman, S.F., Wunderlich, J., Restifo, N.P., Thomasian, A., Downey, S.G., Smith, F.O., Klapper, J., Morton, K., Laurencot, C., White, D.E., and Rosenberg, S.A. (2008). Adoptive cell therapy for patients with metastatic melanoma: Evaluation of intensive myeloablative chemoradiation preparative regimens. J. Clin. Oncol. 26, 5233-5239.

Eshhar, Z. (2008). The T-body approach: Redirecting T cells with antibody specificity. Handb. Exp. Pharmacol. 181, 329-342.

Hombach, A., Hombach, A.A., and Abken, H. (2010). Adoptive immunotherapy with genetically engineered $\mathrm{T}$ cells: Modification of the IgG1 Fc "spacer" domain in the extracellular moiety of chimeric antigen receptors avoids "off-target" activation and unintended initiation of an innate immune response. Gene Ther. 2010 Jun 17. [Epub ahead of print] doi: $10.1038 /$ gt.2010.91

Hoyos, V., Savoldo, B., Quintarelli, C., Mahendravada, A., Zhang, M., Vera, J., Heslop, H.E., Rooney, C.M., Brenner, M.K., and Dotti, G. (2010). Engineering CD19-specific T lymphocytes with interleukin-15 and a suicide gene to enhance their anti-lymphoma/leukemia effects and safety. Leukemia 24, 1160-1170.

Johnson, L.A., Morgan, R.A., Dudley, M.E., Cassard, L., Yang, J.C., Hughes, M.S., Kammula, U.S., Royal, R.E., Sherry, R.M., Wunderlich, J.R., Lee, C.C., Restifo, N.P., Schwarz, S.L., Cogdill, A.P., Bishop, R.J., Kim, H., Brewer, C.C., Rudy, S.F., Vanwaes, C., Davis, J.L., Mathur, A., Ripley, R.T., Nathan, D.A., Laurencot, C.M., and Rosenberg, S.A. (2009). Gene therapy with human and mouse T-cell receptors mediates cancer regression and targets normal tissues expressing cognate antigen. Blood 114, 535-546.

Kershaw, M.H., Westwood, J.A., Parker, L.L., Wang, G., Eshhar, Z., Mavroukakis, S.A., White, D.E., Wunderlich, J.R., Canevari, S., Rogers-Freezer, L., Chen, C.C., Yang, J.C., Rosenberg, S.A., and Hwu, P. (2006). A phase I study on adoptive immunotherapy using gene-modified $\mathrm{T}$ cells for ovarian cancer. Clin. Cancer Res. 12, 6106-6115.

Kieback, E., Charo, J., Sommermeyer, D., Blankenstein, T., and Uckert, W. (2008). A safeguard eliminates T cell receptor gene- modified autoreactive $\mathrm{T}$ cells after adoptive transfer. Proc. Natl. Acad. Sci. U.S.A. 105, 623-628.

Lamers, C.H., Sleijfer, S., Vulto, A.G., Kruit, W.H., Kliffen, M., Debets, R., Gratama, J.W., Stoter, G., and Oosterwijk, E. (2006). Treatment of metastatic renal cell carcinoma with autologous T-lymphocytes genetically retargeted against carbonic anhydrase IX: First clinical experience. J. Clin. Oncol. 24, e20-e22.

Morgan, R.A., Yang, J.C., Kitano, M., Dudley, M.E., Laurencot, C.M., and Rosenberg, S.A. (2010). Case report of a serious adverse event following the administration of $\mathrm{T}$ cells transduced with a chimeric antigen receptor recognizing ERBB2. Mol. Ther. 18, 843-851.

Pule, M.A., Savoldo, B., Myers, G.D., Rossig, C., Russell, H.V., Dotti, G., Huls, M.H., Liu, E., Gee, A.P., Mei, Z., Yvon, E., Weiss, H.L., Liu, H., Rooney, C.M., Heslop, H.E., and Brenner, M.K. (2008). Virus-specific $T$ cells engineered to coexpress tumor-specific receptors: Persistence and antitumor activity in individuals with neuroblastoma. Nat. Med. 14, 1264-1270.

Suntharalingam, G., Perry, M.R., Ward, S., Brett, S.J., CastelloCortes, A., Brunner, M.D., and Panoskaltsis, N. (2006). Cytokine storm in a phase 1 trial of the anti-CD28 monoclonal antibody TGN1412. N. Engl. J. Med. 355, 1018-1028.

Tey, S.K., Dotti, G., Rooney, C.M., Heslop, H.E., and Brenner, M.K. (2007). Inducible caspase 9 suicide gene to improve the safety of allodepleted $\mathrm{T}$ cells after haploidentical stem cell transplantation. Biol. Blood Marrow Transplant. 13, 913-924.

Till, B.G., Jensen, M.C., Wang, J., Chen, E.Y., Wood, B.L., Greisman, H.A., Qian, X., James, S.E., Raubitschek, A., Forman, S.J., Gopal, A.K., Pagel, J.M., Lindgren, C.G., Greenberg, P.D., Riddell, S.R., and Press, O.W. (2008). Adoptive immunotherapy for indolent non-Hodgkin lymphoma and mantle cell lymphoma using genetically modified autologous CD20specific T cells. Blood 112, 2261-2271.

Uckert, W., Kammertöns, T., Haack, K., Qin, Z., Gebert, J., Schendel, D.J., and Blankenstein, T. (1998). Double suicide gene (cytosine deaminase and herpes simplex virus thymidine kinase) but not single gene transfer allows reliable elimination of tumor cells in vivo. Hum. Gene Ther. 9, 855-865.

Vera, J.F., Brenner, M.K., and Dotti, G. (2009). Immunotherapy of human cancers using gene modified T lymphocytes. Curr. Gene Ther. 9, 396-408.

Zhao, Y., Wang, Q.J., Yang, S., Kochenderfer, J.N., Zheng, Z., Zhong, X., Sadelain, M., Eshhar, Z., Rosenberg, S.A., and Morgan, R.A. (2009). A Herceptin-based chimeric antigen receptor with modified signaling domains leads to enhanced survival of transduced T lymphocytes and antitumor activity. J. Immunol. 183, 5563-5574.

Address correspondence to: Dr. Hinrich Abken Zentrum für Molekulare Medizin Köln Klinik I für Innere Medizin Robert-Koch-Str. 21 D-50931 Köln, Germany

E-mail: hinrich.abken@uk-koeln.de

Received for publication June 28, 2010;

accepted July 13, 2010.

Published online: July 30, 2010. 